\title{
Assessment of Urban Resilience to Natural Disasters with a System Dynamics Tool: Case Study of Latvian Municipality
}

\author{
Maksims FEOFILOVS ${ }^{1 *}$, Francesco ROMAGNOLI ${ }^{2}$ \\ ${ }^{1-2}$ Institute of Energy Systems and Environment, Riga Technical University, \\ Azenes iela 12/1, Riga, LV-1048, Latvia
}

\begin{abstract}
Research focuses on linking climate adaptation and disaster risk reduction strategies. The aim of the research is to test an urban resilience assessment tool through a local case study. The tool is based on integrating two methods. Multi-criteria analysis and system dynamics model is used to create a dynamic Urban Resilience Index. For the case study a local medium sized town is chosen in Latvia that is subject to flood risk. The results of the model simulation show that the model is suitable for both short term and long term resilience assessment. Future studies must focus on the precision of such a tool, which in this study could not be evaluated. Overall, the tool presented can contribute to offsetting the existing knowledge gaps between climate adaptation and disaster risk reduction for better policy planning and strengthening urban resilience on the local level.
\end{abstract}

Keywords - Climate adaptation; infrastructure; risk reduction; sustainability

\section{INTRODUCTION}

\subsection{Lack of resilience against natural disaster}

In light of the world's growing population, the increasing level of urbanization from $29 \%$ to $49 \%$ between 1950 and 2005 and the increase in global carbon emissions from fossil-fuel burning during the same time period by almost $500 \%$ [1], the actual consequences of climate-related disasters have increased tremendously [2]. Climate-related disasters between 1998 and 2017 accounted for $91 \%$ of all recorded events and the losses from extreme weather events rose by $251 \%$. In this period, the disaster-hit countries reported losses from climate-related disasters equal to more than two billion dollars, while the real costs of disasters to the global economy are assumed to be up to EUR 429 billion per year. The build-up of urban infrastructure around the world has led to more capital exposure to disasters and consequently increase in disaster losses. Thus, the integration of climate change adaptation and disaster risk reduction policies is crucial for decreasing the vulnerability to disasters of urban areas.

Furthermore, review [3] of progress made on Priority 2 of the Sendai Framework for strengthening disaster risk governance concluded that progress was made for planning and implementation at the international, regional and national levels, however, the available capacity and information for decision making on the local level that would enable synergies

* Corresponding author.

E-mail address: maksims.feofilovs@rtu.lv 
between disaster risk reduction and climate adaptation and overall sustainable strategies is still lacking.

The topicality of this study is also underlined by the current state on the local level in the context of Latvia. According to the predictions reported in Latvia's Adaptation Plan to Climate Change for the Time Period to 2030 [4], the evidence of the recent increase in precipitation in Latvia will grow even more, by $10 \%$ to $21 \%$ until the end of the $21^{\text {st }}$ century, which means floods will occur more often than ever before. Other changes include significant increase in the air temperature; there will be a significant increase in the number of summer days as well as a significant increase in the number of tropical nights. The periods of heat and drought and their frequency will increase. Altogether there is increasing vulnerability of the population in terms of health risks, economic in terms of loss or damage of capital, environmental problems in terms of ecosystem degradation, or even all together. Therefore, the main objective of this study is to contribute to offsetting the knowledge gaps of local governments (i.e. cities, municipalities) on the topic of climate adaptation and disaster risk reduction towards the concept of urban resilience. The study aims to present and test an urban resilience assessment tool through a case study on one of urban areas in Latvia to find the most optimal scenario for local policy planners considering the multi-dimensional nature of urban resilience.

\subsection{Multi-dimensional nature of the research field}

Urban policy making requires careful weighting and evaluation of alternative decisions or policies, but the aspect of multi-dimensional nature and adaptivity of urban systems is causing a real challenge for planning and decision-making regarding climate adaptation and disaster risk reduction. Findings in literature suggest that there is a lack of engagement with complex challenges in urban policy, especially when addressing resilient urban communities and ecosystems. According to [5], the terminological variety and epistemological disjunctions of the research field seem to have made urban policy making even more difficult, because of lack of recognition and reflection, while the existing knowledge gaps have not been reduced or filled.

The urban areas are highly complex systems which develop and change rapidly and have been acknowledged as complex socio-ecological-technical systems [6]. Considering the rapid change and a multi-dimensional nature urban areas are also defined as complex adaptive systems with multiple elements and relationships having an unstable, transformative character, which is hard to fully understand. The interrelationships between elements include natural and social processes, which involve people, nature and culture. Complex adaptive systems behaviour can only be described by non-linear dynamics, which is the result of many feedbacks of multiple elements [7]. Therefore, a framework for evaluating the urban resilience firstly should consider the complexity of the multidimensional nature of urban areas to aid urban policy and decision making [8].

The concept of resilience itself is also of a very comprehensive, multifaceted nature and for this reason can have even several evaluation perspectives, this is very confusing and misleading when attempting to measure it. In recent years resilience has been of great interest for many research areas including engineering and environmental science, which lead to distinguish of engineering resilience, ecological resilience and evolutionary resilience. Depending on the perspective, resilience can have a different focus on system characteristics like recovery, robustness or adaptive capacity, and therefore also a different approach towards measuring resilience, for example, speed of return to steady state, magnitude of disturbance that can be absorbed or coupled systems capacity to co-evolve [9]. 
Recent study on definition of urban resilience concluded that the term itself has not been defined well and proposed a better definition, which addresses urban resilience recognizing it as both socio-ecological and socio-technical networks (including their ability to transform) and considers temporal and spatial scales, in this way capturing multiple possible path ways of looking at urban resilience, [10] considering the ability to return to the desired functions in the face of disturbance as the main parameter. For such definition of urban resilience, the concept of evolutionary resilience is crucial. The concept defines the link between urban planning and adaptation, embedding vulnerability and adaptive capacity over both short-term and long-term [11], thus introducing the connection between resilience to sustainability [12].

Considering the complexity of the given term urban resilience it can be difficult to quantify, but any of the assessment tools can strongly help to increase the understanding and learning, especially when dynamic change in system is described [13].

\subsection{Assessment of urban resilience against natural hazards}

The challenge of assessing urban resilience lies in creation of a consistent methodology that can consider all the uncertainties related to multi-dimensionality of urban areas and complexity of urban resilience. In practice, the theoretical concepts that are difficult to interpret in a measure state are synthesized into a single number with the help of an indicator approach [10]. Through such an approach, usually different criteria can be included into a simple decision-making tool for policy makers, allowing them the comparison between different measurements. Such an approach is very common across climate vulnerability and impact assessments of urban systems, because the use of different criteria can capture the multi-dimensionality of the chosen complex system. Examples of indicator-based approaches for measuring resilience are found in [14] and [15].

Despite the recognition of indicator-based methods in climate relate studies, disadvantages are often reported in literature due to the complexity of the given concept of resilience. One of the most recognized indicators in the research field are Sendai Framework indicators to determine global trends in the reduction of risk and losses, which according to [16] at the current state of use serve for calculating the impact of short-term realized risks, but do not provide enough information to create risk reduction and disaster prevention strategies over the long-term. The lack of research addressing long-term effects in the field of climate change and natural hazards was also mentioned in the study of [17].

Study of [18] reviewed social resilience framework focusing on indicators and found that process oriented indicators that are based on dynamic properties have been largely neglected, and the existing social resilience frameworks are limited for interpreting the actual resilience status of a community. The indicators do not reflect the interactions among the variables in the chosen system and for that reason cannot provide indications for future scenario development. This also means that such approach will lack the definition of a link between socio-economic and environmental aspects in the assessment [19]. Similar flaws of the existing methods was found earlier in methodologies assessing risks to natural hazards [20], where focus lies on static vulnerability, without looking at changes in time or space.

Regarding spatial changes, [21] found that integration of spatial reference to indicator-based measures will not help to fully reflect the concept of resilience if the capacity to adapt or to transform studied systems is not embedded in the indicators. Moreover, it is hard to apply relevant variables or indicators that are practical for every city, therefore, a way to integrate a systemic approach into urban resilience measures should be developed. Similar conclusions found in study of [22] about seeing resilience as a complex of social processes. This view is in line with the socio-ecological perspective, which addresses urban resilience 
as a complex of social processes that allow local communities to self-organize and ensure positive collective action for community survival and wellbeing, instead of seeing urban resilience just as a set of community capacities, assets or capitals, which are often used in indicator based methods.

Among several other methods found in literature that are used to assess processes considering the interrelationship of system variables and having a time reference (Bayesian networks [23]; Input-Output economic model [24]; Agent based model [25], [26]), the system dynamics approach was found to be the most appropriate to analyse the causal relationships among various factors. This approach is based on systemic thinking and is extensively applied in many research fields including in social, economic, ecological, and resource and policy assessment systems.

The System Dynamics (SD) approach has been widely used when modelling complex systems to aid policy planning and decision making. In the study of [19] system dynamics approach was used for creation of a model with integrated economic-social-environmental resource dimensions and indicator index is used to evaluate the urban sustainability performance of each dimension. The results of the model simulation include scenarios for different policies and strategies that can be implemented to guide the development of urbanization. Another study of [27] also found that the SD approach has all the tools offering a useful modelling approach to simulate scenarios in a wide array of disciplines and presented a system dynamics based tool for understanding the system behaviour of sophisticated public utility services and to evaluate the external impact from natural hazards. Study of [28] used a SD model to help optimize water supply strategies considering the economic, social and environmental factors in the short, medium and long-term.

With the consideration of background information in the research field of urban resilience and the current state of the urban resilience assessment tools, this paper is structured in the following way: Methodology part describes the steps performed for a creating the novel urban resilience tool and validating its applicability through a case study; Results part presents the outcomes of the case study; Conclusions are made at the end of the paper.

\section{Methodology}

The research methodology developed for this study is proposed to finally contribute to change in urban resilience measures by providing a tool that allows to discard the assessment of urban resilience of single disciple/dimension within the short-term and move towards the multi-dimensional urban resilience assessment, which includes socio-economic and environmental aspects over both a short-term and long-term perspective. The methodology used for the purpose of this study can recognize the feedbacks between multiple elements of urban area to show the non-linear dynamics behaviour of the socio-ecological and socio-technical systems, thus addressing urban resilience through the perspective of socio-ecological (evolutionary) resilience.

The main methods included in the methodology are SD approach and Multi Criteria Analysis (MCA). The feedbacks modelled within a SD model are suitable for the evaluation of dynamic change in complex systems over time, but, specifically for the purpose of measuring resilience, there is a need to refer to resilience as a quantitative value. The value (expressed as single resilience indicator) is not defined by a SD approach and therefore the MCA approach should be included in terms of an indicator-based index. Such methodology favours transition from conventional indicator-based resilience measures to dynamic indicator-based urban resilience assessment with a SD model. 
The summary of methodology for creating and testing the urban resilience tool is presented in Fig. 1. The methodology is divided in four parts for achieving the main goal of the study. The first part is performed to create the background and define the structure and purpose of the following steps of this study: literature review, definition of the urban resilience and assessment methods and the definition of dynamic problem and hypothesis. Part 2 addresses the selection of indicators, creation of reference index for MCA, integration of MCA into SD model. In Part 3 the SD model is validated for: i) consistency of indicators, ii) consistency of index output; and iii) explanation of the dynamic problem. When the model is validated, the results of urban resilience assessment are presented as the final output.

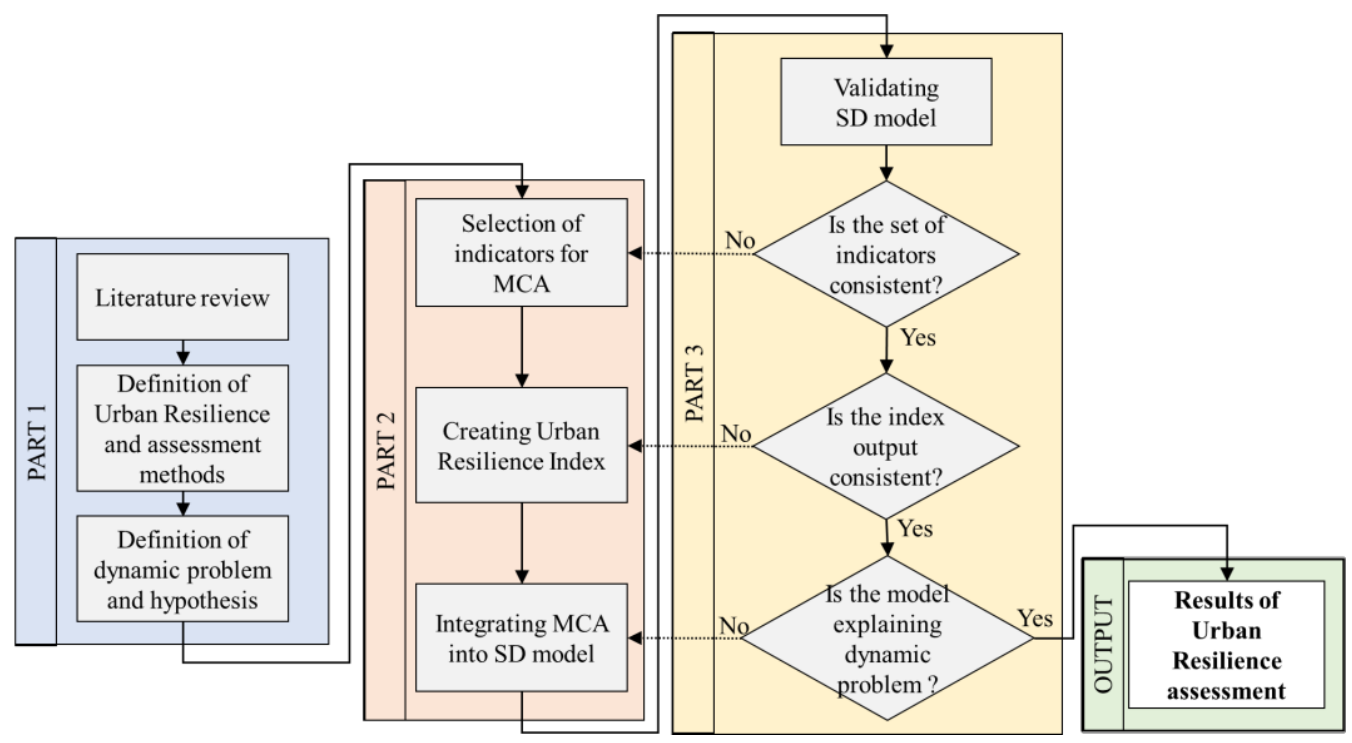

Fig. 1. Summary of methodology of the study.

The methodology chapter of the paper follows the structure: definitions, assessment methods, dynamic problem and hypothesis is introduced in sub-chapter 2.1.; Selection of indicators for MCA and creation of Urban Resilience Index and integration of MCA into SD model in sub-chapter 2.2.; Part 3 on validation of SD model in sub-chapter 2.3. Outputs are presented in the Results Chapter.

\subsection{Definitions, assessment methods, dynamic problem and hypothesis}

According to literature the definition of Urban Resilience was proposed by [10] and refers to the ability of urban systems "...to maintain or rapidly return to desired functions in the face of a disturbance, to adapt to change, and to quickly transform systems that limit current or future adaptive capacity". The definition of urban resilience best fits the application of two methods - SD approach and MCA.

SD approach is commonly used to describe the nonlinear behaviour of complex systems that include social and technical aspects by using stocks, flows and internal feedback loops [29]. This approach can be used to model dynamics and metabolism of systems dealing with interconnections among and between the different factors of the environment in societal, technological, governance and ecological dimensions. SD models allow to understand the 
reason of specific system behaviour and have the potential (when applied on a modelling tool) to hypothesize, test, and refine resilience strategies. The approach is based on linear dynamics and feedback control theory and explains the behaviour of a system through structure that drives the behaviour of the system itself and therefore the feedback loops are the basis of explanation of system behaviour [30].

Complex definition of urban resilience was synthesized into SD model through MCA, which addressed four dimensions of urban areas to create a robust structure for analysis of urban area. Based on the adopted definition of urban resilience, indicators were selected for four distinguished dimensions of urban areas: social, economic, infrastructure and environmental. The given classification of urban area in four dimensions was found to be comprehensive to distinguish the main processes taking place in urban areas in respect to socio-ecological and socio-technological contexts, as presented by concept of urban resilience SD model in a comparative study of two models [31].

Within the context of the selected dimensions for SD model, the study aims to measure urban resilience. The dynamic problem is the change of urban system functionality level over time due to the background structure of the urban system and the way it reacts to an external stressor, represented by Fig. 2. The problematic behaviour is the loss of functionality level in urban systems (Urban system), after which the system can either get back to the normal functionality level thus showing a certain resilience (Urban system with recovery) or maintain a lower functionality level in fact presenting a lower resilience (Urban system without recovery). The hypothesis is that problematic behaviour can be solved by increasing or decreasing the strengths of feedback loops embedded in the urban SD model in order to increase the recovery rate to the normal function level or even have almost no loss of the functionality level (Urban system without loss of functionality level).

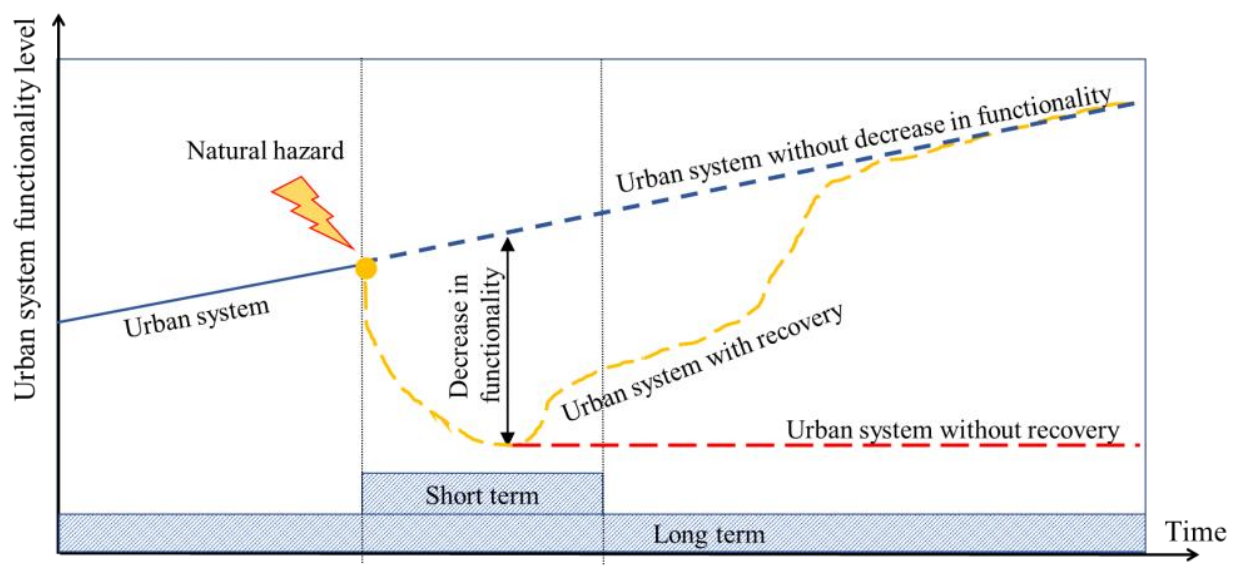

Fig. 2. Dynamic problem that study intends to solve (Urban system: Blue line; Urban system without loss of functionality level: Blue dotted line; Urban system with recovery: Orange dashed line; Urban system without recovery: Red dotted line).

For the purpose of this study, long term and short term are also considered. Short-term addresses the systems behaviour after the natural hazard occurrence, including the response (loss of functionality level) to natural hazards and recovery phase. Long term addresses the system functionality level over a period before and after short term recovery. Study also considers the long-term recovery that can occur due to delay in indirect effects of natural hazard on socio-economical aspects. The inclusion of both time references allows to 
understand what the key feedbacks between dimensions of urban areas are and how changes in different variables affect urban resilience.

\subsection{Selection of indicators, creation of Index and MCA integration into SD model}

To have measurable output of SD model describing the urban resilience, a measure is necessary that is able to distinguish how high or low the resilience of the given urban area. For this purpose, MCA is used with a single value output in the form of Urban Resilience Index $(U R I) . U R I$ is composed of indicators referring to characteristics of urban resilience in each dimension. Indicators must have a reference scale that distinguish if the value of this indicator is low or high for the specific urban area. To understand this relative value of indicator, it can be compared to the same indicator value in other areas. In this study, EUROSTAT data was used to create a reference scale for each indicator.

Next step is to deal with different scale of measure of each indicator by performing normalization of indicators. Several normalization methods were tested in validation of the Urban Resilience Index consistency. Normalized indicators are then used for evaluation of Urban Resilience Index as described by Eq. 1.

$$
U R I=\frac{\sum_{i=1}^{n}\left(x_{i} \cdot w_{i}\right)}{n},
$$

where

$x_{i} \quad$ normalized indicator;

$w_{i} \quad$ weight of indicator;

$i \quad$ indicator number;

$n \quad$ number of indicators.

Urban Resilience Index is defined as the mean average of weighted normalized indicators. Equal weights were assigned to all the indicators in this case study. The indicators were integrated into SD model for evaluation of $U R I$ as shown in Fig. 3. The lines linking dimensions represent the feedbacks considered in the model.

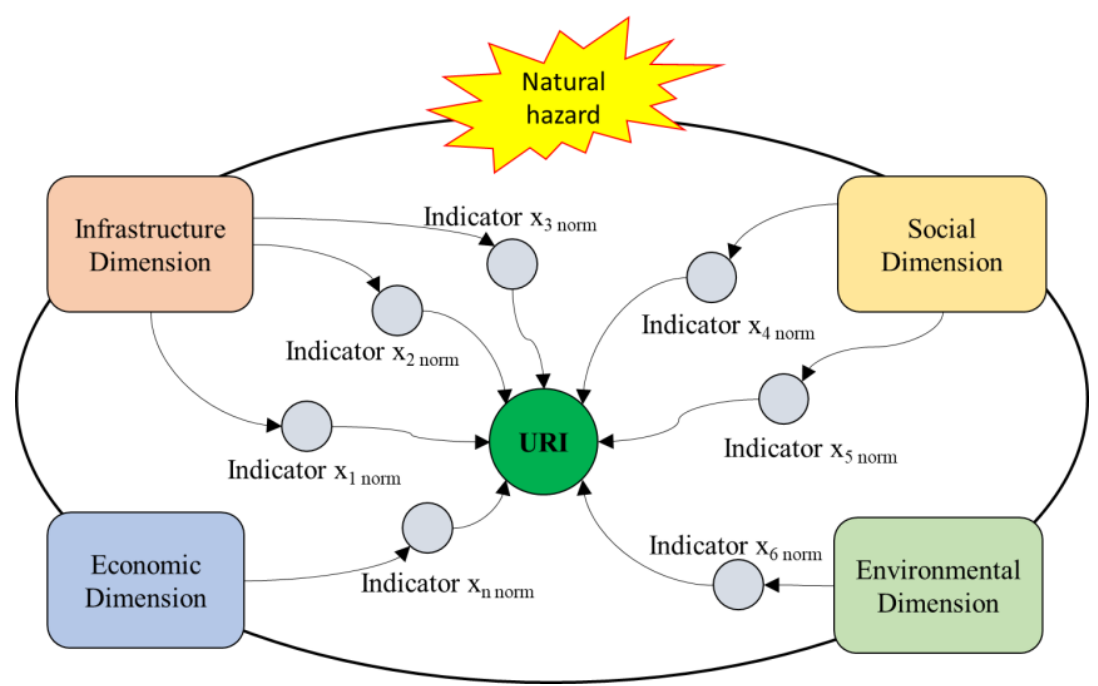

Fig. 3. MCA integration into SD. 
The event disturbing functioning level of the urban area is the natural hazard defined within the SD model as a shock occurring to exposed population and services. The structure of this SD model is created in order to show how urban systems can rapidly return to desired functions in the face of a disturbance or maintain the level of functioning without loss in ideal scenario in the short and long term.

For purpose of this study floods of different magnitudes were considered as natural hazards. The magnitude of floods was defined as flooded area depending on likelihood of occurrence once in 10 years, once in 100 years and 200 years, according to data on national flood risk assessment by the Latvian Environment, Geology and Meteorology Centre for the chosen urban area. The hazard event during the simulation is created by a built-in function RANDOM $(0.100)$ that foresees uniformly distributed generation of number between 0,1 , which is then used as the probability of likelihood of occurrence. The hazard intensity is estimated based on RANDOM number according to logical functions in Eq. (2).

$$
\begin{gathered}
\text { Hazard intensity }=\text { If }(\text { RANDOM }) \geq 99.5 \text { Then }(200) \\
\text { Else If }(\text { RANODM }) \geq 99 \text { Then }(100) \\
\text { Else If }(\text { RANDOM })>=90 \text { Then }(10) \text { Else }(0)
\end{gathered}
$$

For example, if during the simulation step RANDOM $>=99.5$ then the hazard equivalent to magnitude of once in 200 years is used as a shock. In this way, RANDOM function generates a random number every step of the simulation and model transforms into hazard intensity according to likelihood of occurrence of the hazard. This hazard is then transformed into shock to specific variables in dimensions of the urban area.

A brief explanation of causal loops embedded in the urban resilience SD model is presented in Fig. 4. In this illustration, only the main feedbacks between dimensions important for description of the model are shown. Not all the variables included in the model are shown in Fig. 4. The links from variables in four dimensions to indicators (as described by Fig. 3) are not included in Fig. 4.

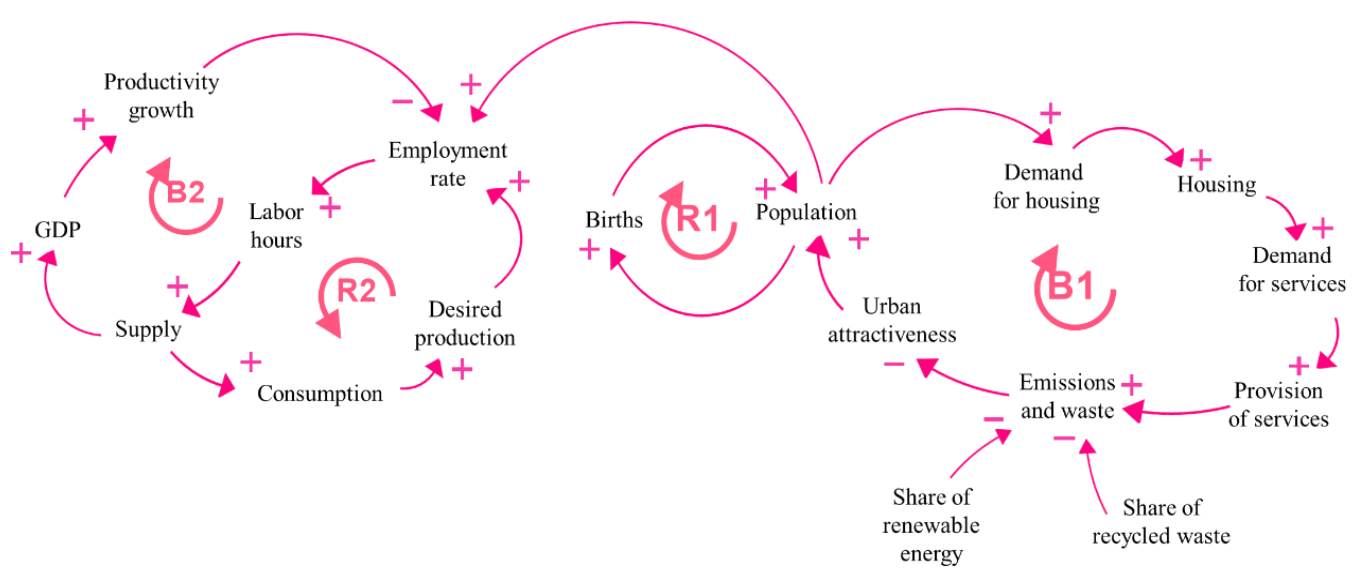

Fig. 4. Causal loop diagram for main feedbacks loops in Urban Resilience SD model. 
The urban resilience SD model structure starts with the definition of urban population in social dimension. Urban population is the core aspect of the urban area, which drives the demand for services that the urban area can provide. To model the link between urban population infrastructure services in infrastructure dimension, a supply-demand balance is created within the structure of the model with the help of flows and stocks. The infrastructure services included in the infrastructure dimension are housing, water supply, wastewater treatment, heat supply, electricity supply. Similarly, environmental dimension services for waste treatment are also defined within the structure of the model with supply-demand balance. Economic dimension includes supply-demand balance structure between supply from inventory, which depends on GDP and imports and demand, which depends on disposable income.

The first important feedback loop is reinforcing loop R1, which governs the population growth. Balancing loop B1 includes variables of social, infrastructure and environmental dimensions. When the value of Urban population variable increases, the Demand for infrastructure services also increases, which leads to higher Emissions and lower Urban attractiveness and consequently the decrease of Urban population through Migration variable. The second important feedback loop is balancing loop R2, which includes the variables of social and economic dimensions. When value of Urban population variable increases, the stock of working age population will increase and thus the Share of employed population can increase under the simulation of economic loop R2. Loop B2 balances the economic sector by satisfying the Demand for consumption through the Supply from inventory.

\subsection{Validation of $S D$ model}

The validation of the created SD model with $U R I$ index and indicators was performed in three steps: validation of indicators, validation of index and validation of SD model structure. First indicator consistency was checked with the structure of the model and with the available data for reference scale in EUROSTAT. Indicators that did not have reference data were excluded from this study, because no quantitative reference to low or high value of indicators existed for normalization and $U R I$ evaluation.

$U R I$ is created from validated indicators. Normalization methods known as Z-score, Minmax and Ranking were tested for this purpose. Normalization of validated indicators was performed in order to put indicators on the same scale. URI is considered validated for consistency when all normalized indicators in index have the same scale of measure, thus have the same scale of impact on the final URI score when equally weighted according to Eq. (1).

Validation of the Urban Resilience SD model was performed in two parts. First, balanced equilibrium simulation was performed for each dimension separately, without any feedbacks on other dimensions and changes of variables over time. Such approach was chosen to validate the consistency of the model structure. The expected output is a linear behaviour without any changes over time. When each dimension included in the model can provide such a consistent output alone, the model is considered to have a consistent structure and further changes of variables over time and feedback loops between separate dimensions can be linked for simulation of the dynamic behaviour.

Second part of the validation is performed within a local case study. To validate the model during the simulation, it is expected that model will show the dynamic behaviour as described in dynamic problem and hypothesis. Such output would be the result of interaction among all the feedbacks loops between variables in different dimensions. 
The validation has used input data taken from a real, medium-sized town exposed to potential flooding in Latvia. Due to the lack of all the local level statistics needed as input data for the model, it is not possible to validate the model according to historical data. The available statistics data was used for most of the variables in the model, but some parts of the model required use of proxy data and therefore, only the tendencies of the dynamic behaviour could be validated without validating the precision of the output. The input values for this simulation are reported in Table A1 in the Annex. A 50-year-long simulation period is used to see how the model captures the feedbacks over the short and long term. It is assumed that the model that can show a consistent output considering all the feedbacks for a 50-year simulation period without errors and has a robust enough structure to be used for future research when more precise data is collected.

\section{Results}

The validation of the model was performed for consistency of indicators. Together 26 indicators were proposed to be included in the MCA for the definition of the SD model. After validating the set of indicators, only 12 indicators were found suitable for application in the final Urban Resilience SD model. These indicators are presented in Table 2.

TABLE 2. INDICATORS SELECTED FOR FINAL URBAN RESILIENCE SD MODEL

\begin{tabular}{|c|c|c|c|}
\hline $\begin{array}{l}\text { Social } \\
\text { dimension }\end{array}$ & $\begin{array}{l}\text { Economic } \\
\text { dimension }\end{array}$ & $\begin{array}{l}\text { Infrastructure } \\
\text { dimension }\end{array}$ & $\begin{array}{l}\text { Environmental } \\
\text { dimension }\end{array}$ \\
\hline $\begin{array}{l}\text { Share of unemployed } \\
\text { population }\end{array}$ & $\begin{array}{l}\text { GDP per } \\
\text { capita }\end{array}$ & $\begin{array}{l}\text { Share of population experiencing } \\
\text { housing deprivation }\end{array}$ & $\begin{array}{l}\text { Waste produced vs } \\
\text { treated }\end{array}$ \\
\hline Youth dependency & & $\begin{array}{l}\text { Share of population with electricity } \\
\text { supply }\end{array}$ & \\
\hline Elderly dependency & & Share of households with inability to & \\
\hline Share of population at & & keep house warm & \\
\hline \multirow{2}{*}{ Share of immigrants } & & $\begin{array}{l}\text { Share of population with access to } \\
\text { water supply }\end{array}$ & \\
\hline & & $\begin{array}{l}\text { Share of population with wastewater } \\
\text { treatment }\end{array}$ & \\
\hline
\end{tabular}

For URI evaluation data gathered from EUROSTAT for chosen indicators was normalized according to Minmax normalization.

$$
x_{i \text { norm }}=\frac{x_{i}-\min \left(x_{i}\right)}{\max \left(x_{i}\right)-\min \left(x_{i}\right)},
$$

where

$\begin{array}{ll}x_{i \text { norm }} & \text { the normalized indicator; } \\ x_{i} & \text { the indicator value before normalization; } \\ \min \left(x_{i}\right) & \text { the minimum value of indicator in EUROSTAT data set; } \\ \max \left(x_{i}\right) & \text { the maximum value of indicator in EUROSTAT data set. }\end{array}$

Besides Minmax normalization, other normalization methods were considered, but did not fit the specifics of index evaluation over time in the SD model. The Z-core method could not be used as after indicator normalization the $\mathrm{Z}$-score values have different scales for each 
indicator. Ranking approach would be similar to the Minmax method, but with a smaller scale of measure, for example 5 ranks. Therefore, the model would not be as sensitive as with the Minmax method, which linearly transforms $x_{i}$ to $x_{i}$ norm and provides output values on a scale of 0 to 1 . According to the Eq. (1) URI is the mean average of weighted normalized indicators and thus also has a scale of 0 to 1 .

During balanced equilibrium validation of Urban Resilience SD model, all four dimensions were separately tested. The model showed that it is possible to have a balanced equilibrium in all parts of the model.

To validate the full urban resilience SD model with feedbacks between four dimensions as described in Fig. 4, simulation was performed using input data derived from the Annex over 50 years without the occurrence of hazards. The output of the simulation for indicators used in $U R I$ assessment is presented in Fig. 5.

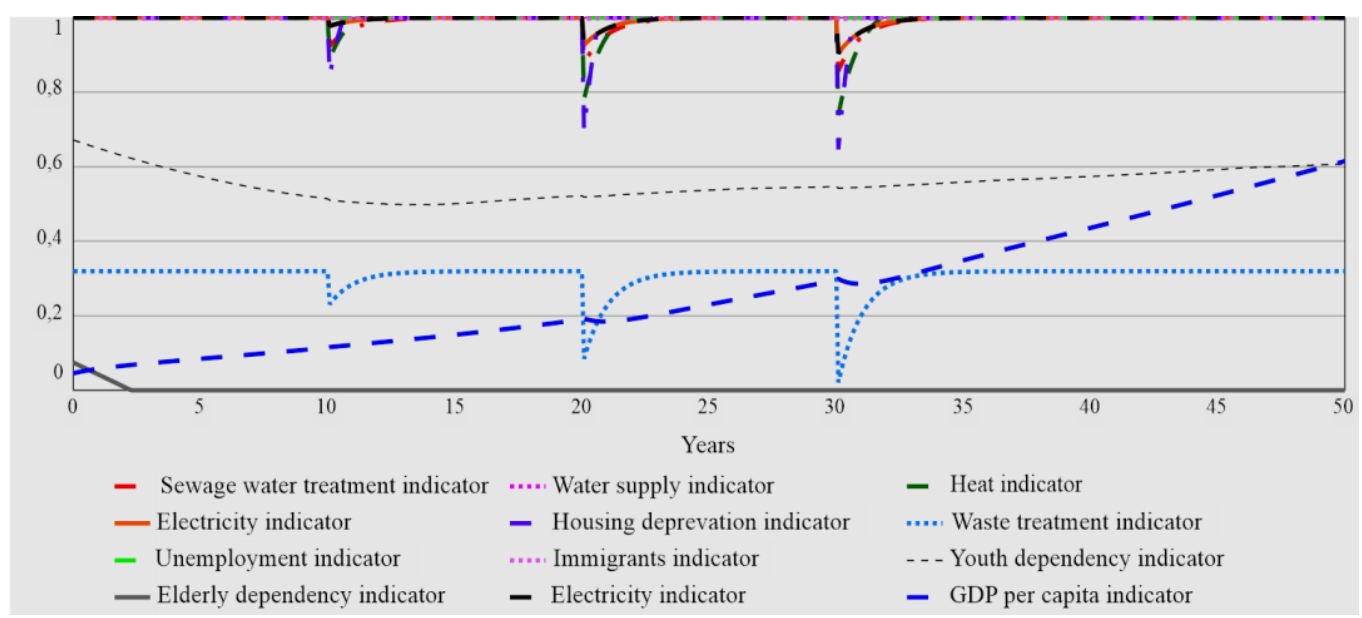

Fig.5. Output of indicators for Urban Resilience SD model simulation without occurrence of natural hazard.

Natural hazard variable is added to the simulation as describe by Eq. (2), however for purpose of presenting the results during the simulation the hazard was generated manually 3 times by at years 10, 20 and 30 and respective results for indicators were received as an outcome.

According to Fig. 5, only some of the selected indicators show change over long term and other over short term. Long term changes are mainly occurring in social and economic indicators: unemployment, youth dependency and elderly dependency, GDG per capita.

The main cause for the trend in Youth dependency and Elderly dependency is the changes of urban population. The number of adults in the area decreases due to migration tendency and thus the youth dependency increases, and youth dependency indicator shows low values. Also, due to migration the number of elderly people decreases, and so the Elderly dependency indicator shows higher value. Values of indicators are not affected by decrease of urban population. For example, decrease of population does not affect the indicators of infrastructure dimension. Also, some of the social dimension indicators like share of population with disabilities and share of population at poverty risk do not change with decrease of population according to this model.

Long term changes also occur in the GDP per capita indicator shows increase in value, while unemployment indicator does not show any change over simulation time while. This is 
in line with the feedbacks considered in model structure. GDP increases with productivity growth. The unemployment does not increase, since there is a decrease of working age population due to migration. Thus, the working age population stock is fully employed.

The Fig. 5. Also shows that it is hard to understand output all the indicators together. The changes in infrastructure indicators occur in short term and overlay. Over the short term it is possible to observe the impact of the hazard on specific parts of the urban system that were not subjected to changes over the long term. The magnitude of the hazard and vulnerability of each urban system defines the severity of impact on urban system and thus on the indicator values. This underlines the need of a single score output. The output of the case study simulation without natural hazard in form of $U R I$ is presented in Fig. 6.

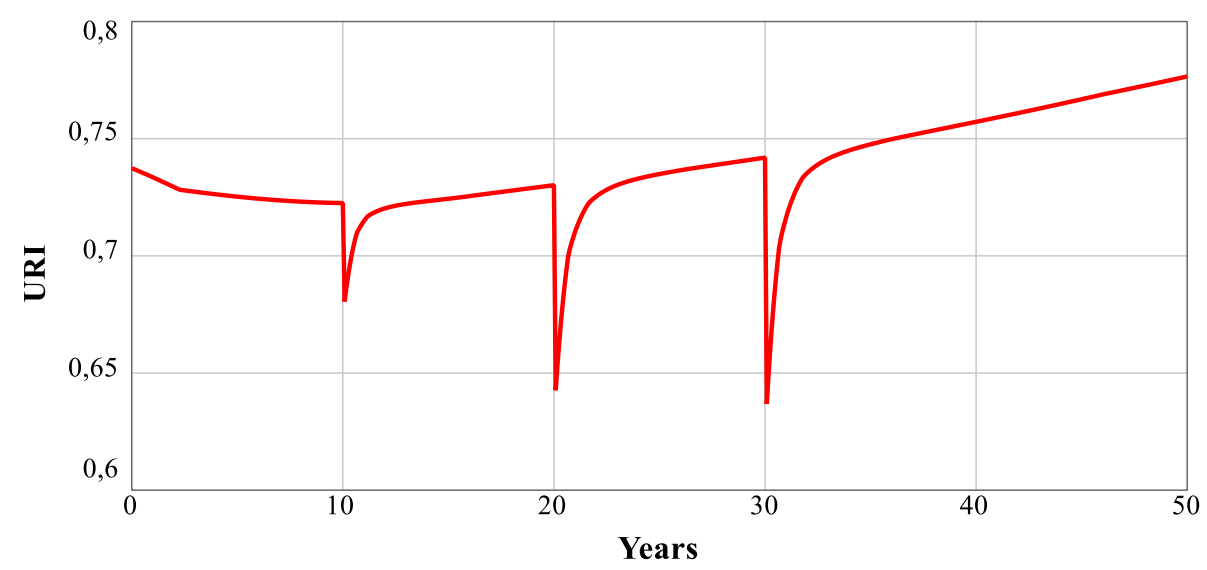

Fig. 6. Output of URI for Urban Resilience SD model simulation without occurrence of natural hazard.

The increase of $U R I$ value over simulation time occurs due to increase in GDP per capita indicator value. The decrease of $U R I$ value at the start of simulation occurs due to increase of Youth dependency and Elderly dependency.

The indicators represent the hazard shock in graph as the "resilience triangle". Also, this effect of "resilience triangle" is reflected in URI (Fig. 6.), thus capturing all aspects of urban resilience in the long and short term.

Overall, the results show that effects of the feedback loops are well represented in the results in terms of dynamic output graphs, and the model can provide an output for $U R I$ in long term simulation based on historical data. The output of this simulation for $U R I$ index can be considered as a baseline for further simulation and testing of different urban resilience scenarios.

\section{Conclusions}

The complex definition of urban resilience was synthesized into a SD model through MCA to create an assessment tool suitable for urban resilience assessment to natural disasters over the short and long term. Based on the adopted definition of urban resilience, indicators were selected for four distinguished dimensions of urban areas: social, economic, infrastructure and environmental. These dimensions were used to create the structure of the SD model.

The study showed that the most appropriate normalization method for purpose of integrating URI into SD model is Minmax. The balanced equilibrium simulation of 
dimensions without feedbacks shows consistency in the output. The results of the local case study showed that the model has the appropriate capacity to present a consistent output over both the short and long term considering the complex feedback loops embedded in the structure of the model. The main causes for dynamic behaviour of the model are the changes in population, that effect demand for infrastructure services in infrastructure dimension and demand in economic dimension.

The model is suitable for modelling the scenarios for policy planning aiming at the increase of urban resilience both in the short and long term. For improving urban resilience in longterm, scenarios should focus on improving changes in population, while for improving urban resilience in the short term, the scenarios must focus on improving the "resilience triangle".

Future studies addressing such an approach must focus on precision of simulation, which mainly depends on the availability of the statistics for local case studies. Unfortunately, due to the application of proxy data in some of the variables, the precision of outputs of this study can be considered imperfect. Availability of local statistics for the long-term period with high granularity would be needed to fully validate the Urban Resilience SD model for local level.

\section{ANNEX}

TABLE A1. InPUT DATA FOR URBAn RESILIENCE SD MODEL FOR CASE STUdy OF TOWN IN LATVIAN CONTEXT

\begin{tabular}{|c|c|c|c|}
\hline Name of variable & Type & Initial value & Unit \\
\hline \multicolumn{4}{|l|}{ Social dimension } \\
\hline Births & Flow & 4329.96 & People/year \\
\hline Young population & Stock & 9447 & People \\
\hline Growing up & Flow & 4329.96 & People/year \\
\hline Mature population & Stock & 36083 & People \\
\hline Ageing & Flow & 4329.96 & People/year \\
\hline Migration & Flow & 400 & People/year \\
\hline Elderly population & Stock & 12024 & People \\
\hline Births per mature person & Variable & 0.12 & Per Person \\
\hline Children deaths & Flow & 3.599307 & People/year \\
\hline Mature people deaths & Flow & 186.90994 & People/year \\
\hline Elderly deaths & Flow & 532.639152 & People/year \\
\hline Children death rate & Variable & 0.000381 & Per Person \\
\hline Mature people death rate & Variable & 0.00518 & Per Person \\
\hline Elderly death rate & Variable & 0.044298 & Per Person \\
\hline Exposure of population & Variable & 0 & People \\
\hline Deaths from natural hazard & Variable & 0 & People \\
\hline Youth dependency & Variable & 0.261813042 & Unitless \\
\hline Elderly dependency & Variable & 0.333231716 & Unitless \\
\hline Share of immigrants & Variable & 0 & $\%$ \\
\hline Share of population at poverty risk & Variable & 0.285 & $\%$ \\
\hline Share of population with disabilities & Variable & 0.597182 & $\%$ \\
\hline Share of unemployed & Variable & 2.77 & $\%$ \\
\hline \multicolumn{4}{|l|}{ Infrastructure dimension } \\
\hline Commissioning of the dwellings & Flow & 0 & Dwellings/year \\
\hline Unoccupied dwellings & Stock & 0 & Dwellings \\
\hline Moving out & Flow & 1223 & Dwellings/year \\
\hline Moving in & Flow & 0 & Dwellings/year \\
\hline Occupied dwellings & Stock & 30000 & Dwellings \\
\hline Damage to occupied dwellings & Flow & 0 & Dwellings/year \\
\hline Recovery of occupied dwellings & Flow & 0 & Dwellings/year \\
\hline Damaged dwellings & Stock & 0 & Dwellings \\
\hline
\end{tabular}




\begin{tabular}{|c|c|c|c|}
\hline Name of variable & Type & Initial value & Unit \\
\hline Construction rate & Variable & 1.060235658 & Dwellings \\
\hline Desired occupied dwellings & Variable & 28777 & Dwellings \\
\hline Desired persons per dwelling & Variable & 0.5 & Persons per Dwelling \\
\hline Shortage of housing per capita & Variable & -0.021249609 & Dwellings per Person \\
\hline Occupied dwellings per capita & Variable & 0.521249609 & Dwellings per Person \\
\hline Exposure of occupied dwellings & Variable & 0 & Dwellings \\
\hline Water supply & Flow & 1095000 & $\mathrm{~m}^{3} /$ year \\
\hline Water for consumption & Stock & 1095000 & $\mathrm{~m}^{3}$ \\
\hline Water demand per capita & Variable & 19.02561073 & $\mathrm{~m}^{3}$ per person \\
\hline Water consumption & Flow & 1095000 & $\mathrm{~m}^{3} /$ year \\
\hline Exposure of water supply & Variable & 0 & $\mathrm{~m}^{3}$ \\
\hline Shortage in water supply & Variable & 0 & $\mathrm{~m}^{3}$ \\
\hline Disruption of water supply & Flow & 0 & $\mathrm{~m}^{3} /$ year \\
\hline Shortage in water supply per capita & Variable & 0 & $\mathrm{~m}^{3}$ per capita \\
\hline Wastewater production & Flow & 930750 & $\mathrm{~m}^{3} /$ year \\
\hline Wastewater & Stock & 930750 & $\mathrm{~m}^{3}$ \\
\hline Wastewater treatment & Flow & 930750 & $\mathrm{~m}^{3} /$ year \\
\hline Exposure of wastewater treatment & Variable & 0 & $\mathrm{~m}^{3}$ \\
\hline Wastewater disruption & Flow & 0 & $\mathrm{~m}^{3} /$ year \\
\hline Wastewater treatment demand & Variable & 930750 & $\mathrm{~m}^{3}$ \\
\hline Wastewater treatment shortage & Variable & 0 & $\mathrm{~m}^{3}$ \\
\hline Share of population with wastewater treatment & Variable & 100 & $\%$ \\
\hline Electricity supply & Flow & 132949.74 & MWh/year \\
\hline Available electricity & Stock & 132949.74 & MWh \\
\hline Electricity consumption & Flow & 132949.74 & MWh/year \\
\hline Disruption of electricity supply & Flow & 0 & $\mathrm{MWh} /$ year \\
\hline Electricity demand & Variable & 132949.74 & MWh \\
\hline Exposure of electricity infrastructure & Variable & 0 & MWh \\
\hline Shortage in electricity supply & Variable & 0 & MWh \\
\hline Shortage of electricity per capita & Variable & 0 & MWh per Person \\
\hline Heat production & Flow & 6390 & MWh/year \\
\hline Heat for consumption & Stock & 6390 & MWh \\
\hline Heat consumption & Flow & 6390 & MWh/year \\
\hline Disruption of heat supply & Flow & 0 & MWh/year \\
\hline Heat demand & Variable & 6390 & MWh \\
\hline Heat demand per capita & Variable & 0.111026167 & MWh per Person \\
\hline Exposure of DH infrastructure & Variable & 0 & MWh \\
\hline Shortage in heat supply & Variable & 0 & MWh \\
\hline Shortage in heat supply per capita & Variable & 0 & MWh per Person \\
\hline Inability to keep house warm & Variable & 0 & $\%$ \\
\hline \multicolumn{4}{|l|}{ Environmental dimension } \\
\hline Waste production & Flow & 63309.4 & $\mathrm{~kg} /$ year \\
\hline Waste & Stock & 63309.4 & $\mathrm{~kg}$ \\
\hline Waste treatment & Flow & 63309.4 & $\mathrm{~kg} /$ year \\
\hline Waste recycling & Variable & 0 & $\mathrm{~kg}$ \\
\hline Waste production factor & Variable & 63309.4 & $\mathrm{~kg}$ \\
\hline Waste vs treated Waste & Variable & 1 & unitless \\
\hline Waste exposure & Variable & 0 & $\mathrm{~kg}$ \\
\hline $\mathrm{CO}_{2}$ Heat & Variable & 115020 & tons/MWh \\
\hline $\mathrm{CO}_{2}$ Electricity & Variable & 53179896 & $\mathrm{~g} / \mathrm{kWh}$ \\
\hline $\mathrm{CO}_{2}$ emission factor for heat & Variable & 18 & Tons \\
\hline $\mathrm{CO}_{2}$ emission factor for electricity & Variable & 400 & $\mathrm{~g}$ \\
\hline $\mathrm{CO}_{2}$ emission & Flow & 60049532.46 & g/year \\
\hline $\mathrm{CO}_{2}$ stock & Stock & 60049532.46 & $\mathrm{~g}$ \\
\hline $\mathrm{NO}_{2}$ emissions & Flow & 1986715.8 & $\mathrm{~g} /$ year \\
\hline $\mathrm{NO}_{2}$ stock & Stock & 1986715.8 & g \\
\hline $\mathrm{NO}_{2}$ emission factor for heat & Variable & 0.01 & $\mathrm{~g} / \mathrm{kWh}$ \\
\hline PM emissions & Flow & 996520.95 & g/year \\
\hline
\end{tabular}




\begin{tabular}{llll}
\hline Name of variable & Type & Initial value & Unit \\
\hline PM stock & Stock & 996520.95 & $\mathrm{~g}$ \\
PM Heat & Variable & 3195 & $\mathrm{~g}$ \\
PM emission factor for heat & Variable & 0.5 & $\mathrm{~g} / \mathrm{kWh}$ \\
\hline Economic dimension & & & \\
\hline Employed & Stock & 29000 & People \\
Employment rate & Flow & 0 & People/year \\
Not employed & Stock & 1000 & People \\
Desired employment & Variable & 14167.18044 & People \\
Hours per worker & Variable & 2000 & $\mathrm{hr} / \mathrm{person}$ \\
Desired labour hours & Variable & 86334360.88 & $\mathrm{hr}$ \\
Labour hours & Variable & 58000000 & $\mathrm{hr}$ \\
Labour exposure & Variable & 0 & $\mathrm{hr}$ \\
GDP & Variable & 590440000 & EUR \\
Supply & Flow & 1039826642 & EUR/year \\
Inventory & Stock & 959355217.7 & EUR \\
Consumption & Flow & 590000000 & EUR/year \\
Export & Flow & 369355217.7 & EUR/year \\
Aggregated demand & Stock & 590000000 & EUR \\
Income & Flow & 510000000 & EUR/year \\
Desired production & Variable & 878883793.8 & EUR \\
Import & Flow & 449386641.6 & EUR/year \\
\hline
\end{tabular}

\section{REFERENCES}

[1] UN-HABITAT. Urbanization and development. Emerging Futures. Nairobi: UN-HABITAT, 2016.

[2] Wallemacq P., UNISDR, CRED. Economic Losses, Poverty and Disasters 1998-2017, 2018.

[3] Djalante R. \& Lassa S. Governing complexities and its implication on the Sendai Framework for Disaster Risk Reduction priority 2 on governance. Progress in Disaster Science 2019:2:100010. https://doi.org/10.1016/j.pdisas.2019.100010

[4] Cabinet of Ministers. Latvian National Plan for Adaptation to Climate Change until 2030. No. 380, 2019.

[5] Wolfram M., Frantzeskaki N. \& Maschmeyer S. Cities, Systems and Sustainability: status and perspectives for research on urban transformations. Current Opinion in Environmental Sustainability 2017:22:18-25. https://doi.org/10.1016/j.cosust.2017.01.014

[6] Basu S., Bale C. S. E., Wehnert T., and Topp K. A complexity approach to defining urban energy systems. Cities 2018:95:102358. https://doi.org/10.1016/j.cities.2019.05.027

[7] Botequilha-leitão A. and Díaz-varela E. R. Performance Based Planning of complex urban social-ecological systems: The quest for sustainability through the promotion of resilience. Sustainable Cities and Society 2020:56:102089. https://doi.org/10.1016/j.scs.2020.102089

[8] Apreda C., Ambrosio V. D., and Di Martino F. A climate vulnerability and impact assessment model for complex urban systems. Environmental Science \& Policy 2018:93:11-26. https://doi.org/10.1016/j.envsci.2018.12.016

[9] Nunes D. M., Pinheiro M. D., and Tomé A. Does a review of urban resilience allow for the support of an evolutionary concept? Journal of Environmental Management 2017:244:422-430. https://doi.org/10.1016/j.jenvman.2019.05.027

[10] Meerow S., Newell J. P., and Stults M. Defining urban resilience: A review. Landscape and Urban Planning 2016:147:38-49. https://doi.org/10.1016/j.landurbplan.2015.11.011

[11] Dhar T. K. and Khirfan L. A multi-scale and multi-dimensional framework for enhancing the resilience of urban form to climate change. Urban Climate 2017:19:72-91. https://doi.org/10.1016/j.uclim.2016.12.004

[12] Diaz-Sarachaga J. M., \& Jato-Espino D. Do sustainable community rating systems address resilience? Cities 2018:93:62-71. https://doi.org/10.1016/j.cities.2019.04.018

[13] Wardekker A. et al. A diagnostic tool for supporting policymaking on urban resilience. Cities 2020:101:102691. https://doi.org/10.1016/j.cities.2020.102691

[14] Scherzer S., Lujala P., \& Ketil Røda J. A community resilience index for Norway: An adaptation of the Baseline Resilience Indicators for Communities (BRIC). International Journal of Disaster Risk Reduction 2018:36:101107. https://doi.org/10.1016/j.ijdrr.2019.101107

[15] Fekete A. Societal resilience indicator assessment using demographic and infrastructure data at the case of Germany in context to multiple disaster risks. International Journal of Disaster Risk Reduction 2018:31:203-211. https://doi.org/10.1016/j.ijdrr.2018.05.004 
[16] Zaidi R. Z. Beyond the Sendai indicators: application of a cascading risk lens for the improvement of loss data indicators for slow-onset hazards and small-scale disasters. International Journal of Disaster Risk Reduction 2017:30:306-314. https://doi.org/10.1016/j.ijdrr.2018.03.022

[17] Hein W., Wilson C., Lee B., Rajapaksa D., and De Moel H. Climate change and natural disasters: Government mitigation activities and public property demand response. Land use policy 2018:82:436-443. https://doi.org/10.1016/j.landusepol.2018.12.026

[18] Saja A. M. A., Goonetilleke A., Teo M., \& Ziyath A. M. A critical review of social resilience assessment frameworks in disaster management. International Journal of Disaster Risk Reduction 2018:35:101096. https://doi.org/10.1016/j.ijdrr.2019.101096

[19] Tan Y., Jiao L., Shuai C., and Shen L. A system dynamics model for simulating urban sustainability performance: A China case study. Journal of Cleaner Production 2018:199:1107-1115. https://doi.org/10.1016/j.jclepro.2018.07.154

[20] Gallina V., Torresan S., Critto A., Sperotto A., Glade T., \& Marcomini A. A review of multi-risk methodologies for natural hazards: Consequences and challenges for a climate change impact assessment. Journal of Environmental Management 2016:168:123-132. https://doi.org/10.1016/j.jenvman.2015.11.011

[21] Cariolet J., Vuillet M., \& Diab Y. Mapping urban resilience to disasters - A review. Sustainable Cities and Society 2019:51:101746. https://doi.org/10.1016/j.scs.2019.101746

[22] Imperiale A. J., \& Vanclay F. Experiencing local community resilience in action: Learning from post-disaster communities. Journal of Rural Studies 2016:47:204-219. https://doi.org/10.1016/j.jrurstud.2016.08.002

[23] Zhou L., Wu X., Xu Z., \& Fujita H. Emergency decision making for natural disasters: An overview. International Journal of Disaster Risk Reduction 2018:27:567-576. https://doi.org/10.1016/j.ijdrr.2017.09.037

[24] Galbusera L., \& Giannopoulos G. On input-output economic models in disaster impact assessment. International Journal of Disaster Risk Reduction 2018:30:186-198. https://doi.org/10.1016/j.ijdrr.2018.04.030

[25] Tidball K. G., \& Aktipis A. Feedback enhances greening during disaster recovery: A model of social and ecological processes in neighborhood scale investment. Urban Forestry and Urban Greening 2018:34:269-280. https://doi.org/10.1016/j.ufug.2018.07.005

[26] Grinberger A. Y., \& Samuels P. Modeling the labor market in the aftermath of a disaster: Two perspectives. International Journal of Disaster Risk Reduction 2018:31:419-434. https://doi.org/10.1016/j.ijdrr.2018.05.021

[27] Phonphoton N., \& Pharino C. A system dynamics modeling to evaluate flooding impacts on municipal solid waste management services. Waste Management 2019:87:525-536. https://doi.org/10.1016/j.wasman.2019.02.036

[28] Xu Z., Yao L., \& Chen X. Computers \& Industrial Engineering Urban water supply system optimization and planning: Bi-objective optimization and system dynamics methods. Comput. Ind. Eng. 2019:142:106373.

[29] Blumberga A., Blumberga D., Bažbauers G., Davidson P., Moxnes E., Dzene I., Barisa A., Žogla G., Dāce E., \& Bērziña A. System Dynamics for Environmental Engineering Students. Riga: Riga Technical University, 2011.

[30] Papachristos G. System dynamics modelling and simulation for sociotechnical transitions research. Environmental Innovation and Societal Transitions 2018:31:248-261. https://doi.org/10.1016/j.eist.2018.10.001

[31] Feofilovs M. et al. Assessing resilience against floods with a system dynamics approach: a comparative study of two models. International Journal of Disaster Resilience in the Built Environment 2020:11(5):615-629. https://doi.org/10.1108/IJDRBE-02-2020-0013 